\title{
Efficacy and Safety of Budesonide in the Treatment of Eosinophilic Esophagitis: Updated Systematic Review and Meta-Analysis of Randomized and Non-Randomized Studies
}

\author{
Prashanth Rawla ${ }^{1} \mathbb{D} \cdot$ Tagore Sunkara $^{2} \cdot$ Krishna Chaitanya Thandra $^{3} \cdot$ Vinaya Gaduputi $^{4}$
}

Published online: 2 November 2018

(c) The Author(s) 2018

\begin{abstract}
Background and Objective Eosinophilic esophagitis (EE) is an immune/antigen-driven inflammation that causes esophageal dysfunction. Budesonide has shown promising effect in the management of EE in multiple studies, and we therefore conducted this systematic review/meta-analysis to assess budesonide efficacy and safety in order to provide more updated and robust evidence.

Methods In April 2018, we conducted a systematic electronic search through four databases: PubMed, Scopus, Web of Science (ISI), and Cochrane Central. All original studies reporting the efficacy of budesonide in the treatment of EE were included in our meta-analysis. The Cochrane Collaboration tool was employed to assess the risk of bias among included randomized controlled trials, while the Newcastle-Ottawa Scale was used for non-randomized studies.

Results A total of 12 studies including 555 participants were included in our review. Budesonide showed marked efficacy at the level of histological response compared to placebo [risk ratio (RR) (95\% confidence interval (CI)) 11.93 (4.82-29.50); $p>0.001]$. Analysis of randomized and non-randomized studies revealed considerable reduction in eosinophil count, with a mean difference (MD) $(95 \%$ CI) of $-69.41(-105.31$ to $-33.51 ; p<0.001)$ and $46.85(33.93-59.77 ; p<0.001)$, respectively. Similarly, there was a marked improvement in the clinical symptoms via the analysis of randomized and non-randomized studies, with an RR $(95 \% \mathrm{CI})$ of $1.72(1.22-2.41 ; p=0.002)$ and MD $(95 \% \mathrm{CI})$ of $2.45(0.76-4.15 ; p=0.005)$, respectively. Conclusion Budesonide showed significant effect at all treatment endpoints. However, since budesonide carries a risk of candidiasis and our inferences are based only on a small number of included studies, more research is warranted to clarify these results.
\end{abstract}

Electronic supplementary material The online version of this article (https://doi.org/10.1007/s40268-018-0253-9) contains supplementary material, which is available to authorized users.

Prashanth Rawla

rawlap@gmail.com

Tagore Sunkara

tagoresunkara@hotmail.com

Krishna Chaitanya Thandra

kc_thandra@yahoo.com

Vinaya Gaduputi

drvinayvittal@yahoo.com
1 Department of Internal Medicine, SOVAH Health, 320 Hospital Dr, Martinsville, VA 24112, USA

2 Division of Gastroenterology and Hepatology, The Brooklyn Hospital Center, 121 Dekalb Ave, Brooklyn, NY 11201, USA

3 Department of Critical Care Medicine, Memorial Sloan Kettering Cancer Center, New York, NY, USA

4 Division of Gastroenterology, SBH Health System, 4422 Third Ave, Bronx, NY 19457, USA 


\section{Key Points}

Topical corticosteroids are the first-line of treatment of eosinophilic esophagitis (EE) after resistance to proton pump inhibitors.

Previous meta-analysis reported significant efficacy of budesonide in EE but they included randomized studies only.

A large-scale meta-analysis of randomized and non-randomized studies showed that budesonide has considerable effect at all treatment endpoints.

\section{Introduction}

Eosinophilic esophagitis (EE) is a worldwide chronic immune/antigen-driven inflammation of the esophagus manifested mainly with dysphagia and food impaction and characterized by elevated levels of eosinophils in the histopathological examination of an esophageal biopsy [1]. The clinical features of EE may differ with age; failure to thrive and food rejection are reported in young children, vomiting and food regurgitation occur in older children, while heartburn, food impaction, and dysphagia can be presented in adults [2]. EE is associated with other atopic conditions such as eczema, allergic rhinitis, and asthma [3, 4]. EE is more common in males, and can affect all ages [3]. Based on the consensus guidelines for the diagnosis of $\mathrm{EE}$, a recent study conducted between 2011 and 2016 reported an incidence rate of $24 \mathrm{EE}$ cases per 100,000 children per year, whereas the 5-year prevalence rate was 118 cases per 100,000 children [5]. More recently, another large cross-sectional study showed increasing incidence rates in the past 15 years, in both adults and children [6].

Unfortunately, the exact etiology of EE has not yet been clearly understood; however, most research studies support immune-mediated reactions [4]. Food allergens are considered substantial immunity triggers in the pathophysiology of EE, and the most commonly identified food allergens are dairy, soy, eggs, wheat, peanuts/treenuts, and fish/seafood. The six food elimination diet (SFED) approach relies on eliminating these specific food allergens [7, 8]. Moreover, environmental allergens have also been involved in the incidence of EE [9], and this has been emphasized by a large, recently conducted cohort study $[10,11]$. A recently updated worldwide consensus diagnostic criteria for EE states that EE should be diagnosed when there are symptoms of esophageal dysfunction beside at least 15 eosinophils per high-power field (eos/hpf) on esophageal biopsy and after a thorough assessment of other non-EE disorders that could potentially be attributed to esophageal eosinophilia [12]. Proton pump inhibitors (PPIs), which are commonly used to diagnose EE by ruling out gastroesophageal reflux disease (GERD) [2], are, according to this updated evidence, better classified as a treatment of esophageal eosinophilia that may be due to EE rather than as a diagnostic criterion for EE [12]. The biopsy can detect eosinophils in the superficial epithelium, and more than 15 or 20 eos/hpf is confirmative [13]; recent guidelines report that $15 \mathrm{eos} / \mathrm{hpf}$ is the cut-off point of EE diagnosis [12]. Various endoscopic scoring systems are being developed as endoscopic outcome measures to identify individuals with EE and to follow their response to treatment; the Endoscopic Reference Score (EREFS) is a validated system used for initial diagnosis and treatment follow-up of EE [14]. Esophageal diseases, especially EE, can be assessed by the means of patient-related outcome (PRO) and clinician-reported outcome (ClinRO) measures. PRO incorporates various measures of symptom severity, functioning (disability), health status, health-specific quality of life, 'general' quality of life, and general health perceptions $[15,16]$. Various PRO instruments have been developed and validated for the assessment of EE-especially clinical response to treatment, including the Eosinophilic Esophagitis Activity Index (EEsAI) and Dysphagia Symptom Questionnaire (DSQ). Several factors are incorporated in the EEsAI tool that assess dysphagia, behavioral adaptation to dysphagia, and pain with swallowing [17], while the DSQ has been shown to be content valid and is currently being further evaluated in a number of trials [16].

The current approaches to the management of EE comprise dietary elimination, endoscopy, and corticosteroids [18]. Although specific food elimination may be safe and efficacious, patient compliance is an issue [2]. While both approaches (pharmacological and food elimination diet) seem promising in managing EE, a recent meta-analysis concluded that both approaches have the same magnitude of histologic and symptomatic response [19]; however, the effectiveness of food elimination should be tempered by the absence of a randomized study and the potential challenges of adherence to such diets [20,21]. It has also been reported that a food elimination diet is expensive, not palatable, and associated with marked weight loss, and thus results in high rates of dropout and non-compliance [22]. In 2002, a study revealed the ability of skin prick testing and patch testing to identify potential causative foods that might attribute to the pathogenesis of EE [23]. Later, it was reported that dietary management can benefit EE patients without the need for skin tests [24]. More recently, the use of skin-patch testing in food-related allergic disease per se has been questioned, and it was reported that such tests-disliked by both patients and clinicians-should not be used in EE [25]. In some cases, it may be necessary to remove the impacted food and dilate the esophagus via endoscopy; however, this 
carries the risk of perforation [3]. Thus, medical treatment with PPIs, which are effective remedies with few risks and low costs, should be considered first. Also, corticosteroids, specifically budesonide and fluticasone, which can inhibit maturation and activation of eosinophils through suppression of the release of their stimulating cytokines, have been proven effective in managing EE [26]. A network meta-analysis in 2016 deduced no statistically significant difference between PPIs and corticosteroids; however, their inferences were limited by the risk of bias and the small number of study participants [27]. In the same year, a meta-analysis of randomized controlled trials (RCTs) reported corticosteroids as having a promising role in histological remission of EE, but not a comparable role in relieving the clinical complaints [28]. However, there are contradictory results from recent RCTs, in which budesonide induced improvement of clinical symptoms as well as significant histological remission [29, 30]. Moreover, the previous systematic reviews and metaanalysis [27, 28] did not include non-randomized studies and only pooled the RCTs as a well-designed study, whereas it has been recommended that these studies not be excluded from meta-analysis [31]. Therefore, we aimed to conduct an updated large-scale systematic review and meta-analysis of randomized and non-randomized studies to assess the efficacy and safety of budesonide in the treatment of EE in both adults and children.

\section{Methods}

\subsection{Search Strategy and Selection Criteria}

Based on the recommendations of Preferred Reporting Items for Systematic Reviews and Meta-Analyses (PRISMA) [32], we conducted a systematic review of literature with the aim of meta-analyzing all relevant data. We performed an electronic search using four databases-PubMed, Scopus, Web of Science (ISI), and Cochrane Central-to retrieve all potentially relevant articles. The following integrated search terms were used to gather all related articles: (Budesonide OR Pulmicort) AND (Eosinophilic esophagitis OR eosinophilic oesophagitis OR allergic oesophagitis). MeSH (Medical Subject Headings) terms used were "Budesonide" and "Eosinophilic Esophagitis". In addition, manual searching of reference lists of included trials was carried out. There was no search filtering applied with regard to language, year, and design. Three reviewers blindly screened titles and abstracts for eligibility according to our inclusion and exclusion criteria. Inclusion criteria were as follows: (1) original articles reporting the use of budesonide in EE; (2) articles reporting data on humans; and (3) no restriction was made with respect to language, sex, age, and area. Exclusion criteria were as follows: (1) case reports, case series, letters, comments, and review articles; (2) data cannot be extracted; (3) overlapped dataset; (4) abstract-only papers; (5) animal or in vitro studies; and (6) duplication and irrelevant data.

\subsection{Data Extraction}

The authors of this meta-analysis independently extracted relevant data. Firstly, a pilot data extraction was undertaken for three articles to determine the data reported. After that, a standardized data extraction form was constructed and any disagreement was resolved through discussion and consensus between the reviewers. Retrieved data comprised baseline characteristics of study subjects and outcomes such as histological response, eosinophil count, and clinical response.

\subsection{Statistical Analysis}

All data were analyzed using $\mathrm{R}$ statistical software version 3.4.4 [33]. First, we calculated the effect size [risk ratio (RR) or mean difference (MD)] and associated standard errors [34] for drug versus control or pre- versus post-treatment groups, and then all data were pooled with the help of the 'meta' package for R [35]. A fixed-effect model [36] was used when there was no evidence of heterogeneity between studies; otherwise, a random-effects model was chosen. Heterogeneity between studies was evaluated using the $Q$ statistic and $I^{2}$ test, which describes the percentage of variability in the effect estimates [37, 38].

\section{Results}

\subsection{Literature Search}

The electronic search yielded 297 references from the four databases. After excluding duplicates and title/abstract screening, we had 20 relevant papers for full-text screening. Of those, seven non-randomized [30, 39-44] and five randomized [29, 45-48] studies were eligible for meta-analysis. The manual search of references did not find any additional papers (Fig. 1).

\subsection{Baseline Characteristics of Randomized and Observational Studies Eligible for Meta-Analysis}

Five RCTs [29, 45-48] including 300 cases with a mean age ranging from 7.8 to 46.5 years were included and metaanalyzed. Most participants were males (78.33\%) and the follow-up varied from 2 to 12 weeks. Detailed data on the baseline characteristics of the included participants are shown in Table 1. Quality assessment of the included RCTs 


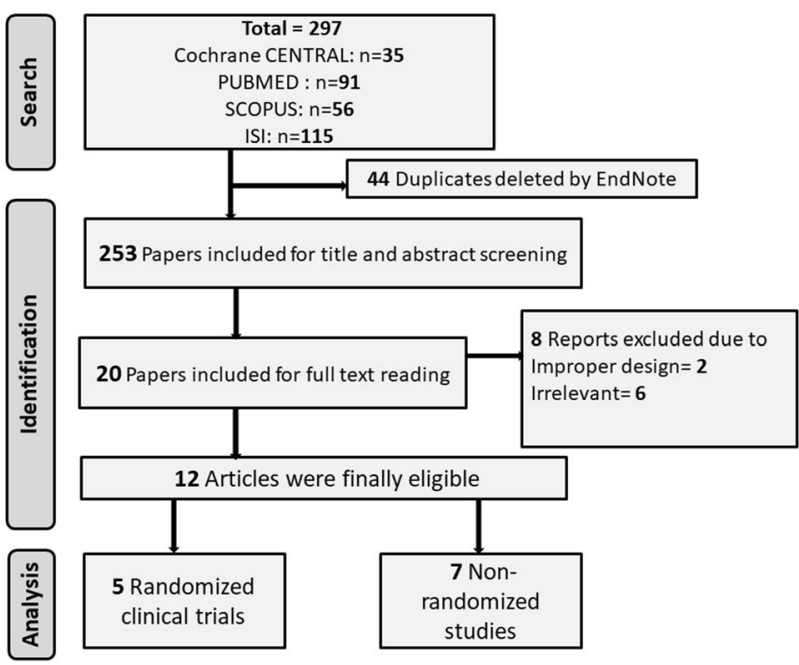

Fig. 1 Flow diagram of selection and screening of the studies was carried out using the Cochrane Collaboration's quality assessment tool [49]. Each domain was evaluated as having a low, high, or unclear risk of bias. Results of the quality assessment for RCTs are summarized in Electronic Supplementary Material Table 1A. In addition, seven nonrandomized studies [30, 39-44] including 255 participants were included, most of whom were males [190 (74.5\%)]. The age of participants, intervention, and follow-up in these studies are summarized in Table 2. Quality of evidence has been assessed using the Newcastle-Ottawa Scale for quality assessment of non-randomized studies [50]. The assessment of each domain was categorized as good, fair, and poor using a scoring system from 0 to 4 stars; this is discussed in detail in Electronic Supplementary Material Table 1B.

\subsection{Therapeutic Efficacy and Safety}

\subsubsection{Histological Response and Eosinophil Count}

Through a meta-analysis of five RCTs including 245 patients, our results showed marked efficacy of budesonide

Table 1 Baseline characteristics of randomized clinical trials

\begin{tabular}{|c|c|c|c|c|c|c|c|c|c|}
\hline \multirow[t]{2}{*}{ First author/year } & \multicolumn{2}{|c|}{ Sample size $(n)$} & \multicolumn{2}{|c|}{$\begin{array}{l}\text { Age (years) [mean } \\
\text { (SD)] }\end{array}$} & \multicolumn{2}{|c|}{ Males $[n(\%)]$} & \multirow[t]{2}{*}{ Route/dose } & \multirow{2}{*}{$\begin{array}{l}\text { Histologic diagnos- } \\
\text { tic criteria: (eos/ } \\
\text { hpf) }\end{array}$} & \multirow{2}{*}{$\begin{array}{l}\text { Follow- } \\
\text { up } \\
\text { (weeks) }\end{array}$} \\
\hline & Cases & Controls & Cases & Controls & Cases & Controls & & & \\
\hline Dellon/2016 [29] & 51 & 42 & $22.3(7.9)$ & $20.8(7.5)$ & $35(69)$ & $29(69)$ & $\begin{array}{l}\text { Oral suspen- } \\
\text { sion } / 2 \mathrm{mg} \text { twice } \\
\text { daily }\end{array}$ & $\geq 15$ & 12 \\
\hline \multirow[t]{3}{*}{ Gupta/2015 [45] } & 17 & 18 & $8.6(6.18)$ & $9.8(4.3)$ & $14(82.4)$ & $13(72.2)$ & $\begin{array}{l}\text { Oral suspension/low } \\
\text { dose }(0.35 \mathrm{mg})\end{array}$ & $\geq 20$ & 12 \\
\hline & 19 & & $10.2(4.89)$ & & $17(89.5)$ & & $\begin{array}{l}\text { Oral suspension/ } \\
\text { medium dose } \\
(1.4 \mathrm{mg})\end{array}$ & & \\
\hline & 17 & & $7.9(4.39)$ & & $13(76.5)$ & & $\begin{array}{l}\text { Oral suspension/high } \\
\text { dose }(2.8 \mathrm{mg})\end{array}$ & & \\
\hline \multirow[t]{3}{*}{ Miehlke/2015 [46] } & 19 & 19 & $38.9(12.6)$ & $36.3(9.9)$ & $17(89.5)$ & $16(84.2)$ & $\begin{array}{l}\text { Orodispersible/ } \\
\text { BET2 (1 mg/day) }\end{array}$ & $\geq 20$ & 2 \\
\hline & 19 & & $37.2(13.9)$ & & $16(84.2)$ & & $\begin{array}{l}\text { Orodispersible/ } \\
\text { BET2 (2 mg twice } \\
\text { daily) }\end{array}$ & & \\
\hline & 19 & & $46.5(14.1)$ & & $14(73.7)$ & & $\begin{array}{l}\text { Oral viscous suspen- } \\
\text { sion/BVS } 2 \text { (5 mL/ } \\
\text { day) }\end{array}$ & & \\
\hline Straumann/2010 [47] & 18 & 18 & $33.1(13.1)$ & $38.2(12.4)$ & $17(94.44)$ & $14(77.78)$ & $\begin{array}{l}\text { Oral suspen- } \\
\text { sion/1 mg twice } \\
\text { daily }\end{array}$ & $\geq 20$ & 2 \\
\hline Dohil/2010 [48] & 15 & 9 & $(1-17)^{\mathrm{a}}$ & $(2-16)^{\mathrm{a}}$ & $12(80)$ & $8(88.89)$ & $\begin{array}{l}\text { Oral viscous/OVB } \\
2 \mathrm{mg} \text { in } \\
\text { those } \geq 5 \mathrm{feet} \\
\text { tall and } 1 \mathrm{mg} \text { in } \\
\text { those }<5 \mathrm{feet}\end{array}$ & $\geq 20$ & 12 \\
\hline
\end{tabular}

$B E T$ budesonide effervescent tablet for orodispersible use, $B V S$ budesonide viscous suspension, eos/hpf eosinophils per high-powered field, $O V B$ oral viscous budesonide, $S D$ standard deviation

${ }^{\text {a }}$ Range 
Table 2 Baseline characteristics of non-randomized studies

\begin{tabular}{|c|c|c|c|c|c|c|}
\hline First author/year & Sample size & $\begin{array}{l}\text { Age (years) } \\
{[\text { mean }} \\
(\mathrm{SD})]\end{array}$ & Males $[n(\%)]$ & Route/dose & $\begin{array}{l}\text { Histologic diag- } \\
\text { nostic criteria } \\
\text { (eos/hpf) }\end{array}$ & Follow-up \\
\hline Reed/2018 [39] & 48 & $33.6(16.1)$ & $33(69)$ & $\begin{array}{l}\text { Compounded viscous budesonide } \\
\text { suspension } / 1 \mathrm{mg} / 8 \mathrm{~mL}\end{array}$ & $>15$ & Mean $=13.2$ months \\
\hline Rubinstein/2017 [40] & 8 & $10(4)$ & $8(100)$ & $\begin{array}{l}\text { OVB/patients }<10 \text { years received } \\
1 \mathrm{mg} / \text { day and those }>10 \text { years } \\
\text { received } 2 \mathrm{mg} / \text { day }\end{array}$ & $>15$ & 10 weeks \\
\hline Fable/2017 [41] & 68 & $11(5)$ & $55(81)$ & $\begin{array}{l}\text { Inhalation/20 patients on FP } \\
110-220 \mu \mathrm{g} / \mathrm{puff} \\
\text { Oral/48 patients on OVB } \\
0.5-1 \mathrm{mg} / 2 \mathrm{~mL} \text { (twice daily) }\end{array}$ & $>15$ & $8-12$ weeks \\
\hline Oliva/2016 [30] & 36 & $12(5-18)^{\mathrm{a}}$ & $21(58.33)$ & $\begin{array}{l}\text { Pre-prepared OVB suspen- } \\
\text { sion } / 0.2 \mathrm{mg} / \mathrm{mL} \text {, patients took } \\
2-4 \mathrm{mg} / \text { day morning and even- } \\
\text { ing doses, based on height }\end{array}$ & $>15$ & 36 weeks \\
\hline Nennstiel/2016 [43] & 20 & $34(11)$ & $19(95)$ & $\begin{array}{l}\text { Liquid budesonide suspen- } \\
\text { sion } / 1 \mathrm{mg} / 2 \mathrm{~mL} \text { twice daily }\end{array}$ & $\geq 15$ & 8 weeks \\
\hline Aceves/2007 [44] & 20 & 5.5 & $17(85)$ & $\mathrm{OVB} / 1-2 \mathrm{mg}$ daily based on age & $\geq 24$ & $3-4$ months \\
\hline
\end{tabular}

eos/hpf eosinophils per high-powered field, $F P$ fluticasone propionate, $O V B$ oral viscous budesonide, $S D$ standard deviation

${ }^{\mathrm{a}}$ Median (range)

at the level of histological response compared to placebo [RR (95\% CI) 11.93 (4.82-29.50); $p<0.001]$. No significant heterogeneity was found among the included RCTs $\left(I^{2}=0 \% ; p=0.776\right)$ (Fig. 2a). In addition, biopsies revealed that patients taking budesonide $(n=82)$ had considerable reduction in their eosinophil count compared with those taking placebo $(n=65)$, with an MD $(95 \%$ CI) of -69.41 $(-105.31$ to $-33.51 ; p<0.001)$. However, significant heterogeneity was found between the studies $\left(I^{2}=75 \% ; p=0.017\right)$ (Fig. 2b). In the same context, six non-randomized studies including 187 patients showed a significant decline in the mean eosinophilic count in patients who received budesonide compared with before treatment [MD (95\% CI) 46.85 (33.93-59.77); $p<0.001]$. Significant heterogeneity between studies was noticed $\left(I^{2}=84 \% ; p<0.001\right)$ (Fig. 2c).

\subsubsection{Clinical Response}

Pooling three RCTs $(n=147)$ revealed marked improvement in clinical symptoms for patients taking budesonide, with $72 \%$ more improvement than in the placebo group [RR (95\% CI) $1.72(1.22-2.41) ; p=0.002]$. No significant heterogeneity was found between results $\left(I^{2}=12 \% ; p=0.321\right)$ (Fig. 3a). Additionally, results from three non-randomized studies showed a significant decrease in mean clinical scores for patients after budesonide treatment compared with before treatment [MD (95\% CI) $2.45(0.76-4.15) ; p=0.005]$. Nevertheless, a significant heterogeneity was found between the analyzed studies $\left(I^{2}=79 \% ; p=0.005\right)$ (Fig. 3b).

\subsubsection{Endoscopic Changes}

The results from four non-randomized studies showed a significant decrease in endoscopic abnormalities for patients $(n=156)$ who underwent treatment with budesonide compared with before treatment [RR (95\% CI) 1.61 (1.41-1.84); $p<0.001]$. The highest reduction was in esophageal furrows $(\mathrm{RR}=2.23)$ followed by white specks/plaques/exudates $(\mathrm{RR}=1.67)$ (Fig. 4a). In the same context, mean esophageal scores were also reduced in patients treated with budesonide compared with pre-treatment scores [MD (95\% CI) 2.24 (0.59-3.90); $p=0.008$ ] (Fig. 4b).

\subsubsection{Incidence of Candidiasis}

A meta-analysis conducted using four RCTs including 227 subjects showed an increased risk of candidiasis with the use of budesonide compared with placebo (RR [95\% CI] 3.29 $[0.74-14.70] ; p=0.119)$; however, this finding is insignificant. No significant heterogeneity was found between results $\left(I^{2}=0 \% ; p=0.914\right)$ (Fig. 5).

\section{Discussion}

EE is a clinical condition characterized clinically by esophageal dysfunction and histologically by a high eosinophil count per high-power field. Patients with EE have used topical corticosteroids as a first-line remedy after PPI resistance [51]. However, there are an increasing number of 
A

Study

Experimental Control

Dellon/2016/USA

Dohil/2010/USA

Gupta/2015/USA

Miehlke/2015/International

Straumann/2010/USA

Events Total Events Total

Fixed effect model

$\begin{array}{llll}19 & 49 & 1 & 38\end{array}$

$\begin{array}{llll}13 & 15 & 0 & 9\end{array}$

$21 \quad 39 \quad 0 \quad 21$

$\begin{array}{llll}18 & 19 & 0 & 19\end{array}$

$\begin{array}{llll}13 & 18 & 2 & 18\end{array}$

Heterogeneity: $l^{2}=0 \%, \tau^{2}=0, p=0.776$

Test for overall effect: $z=5.366(p<0.001)$

105

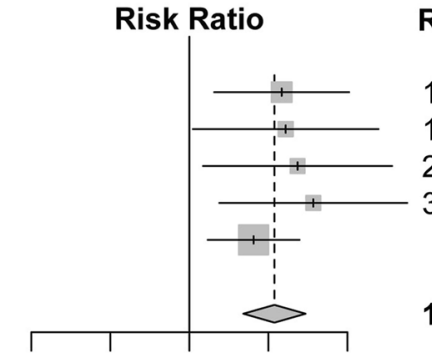

RR $\quad 95 \%-\mathrm{Cl}$

Weight

$14.73[2.06 ; 105.21] \quad 21.2 \%$

$16.55[1.11 ; 247.39] \quad 11.2 \%$

$23.41[1.49 ; 367.66] \quad 10.8 \%$

$37.00[2.39 ; 571.87] \quad 10.9 \%$

$6.50[1.71 ; 24.77] \quad 45.8 \%$

$11.93[4.82 ; 29.50] 100.0 \%$

Favors Placebo Favors Budesonide

B

\section{Study}

Dellon/2016/USA

Dohil/2010/USA

Straumann/2010/USA

Random effects model 82

Heterogeneity: $I^{2}=75 \%, \tau^{2}=749.807, p=0.017$

Test for overall effect: $z=-3.790(p<0.001)$

\begin{tabular}{lrl}
\multicolumn{3}{c}{ Experimental } \\
Total & Mean SD \\
& & \\
49 & -117.00 & 41.0000 \\
15 & -61.80 & 37.3000 \\
18 & -62.70 & 38.9000
\end{tabular}

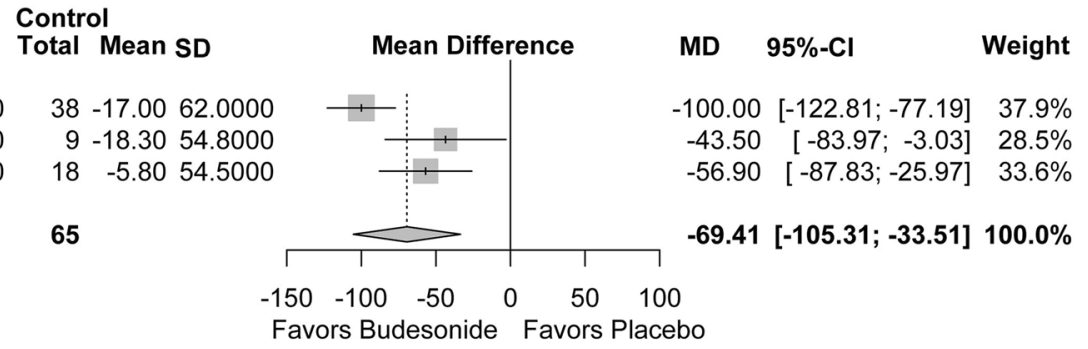

Post

Total Mean SD

$\begin{array}{lll}8 & 2.63 & 3.7000\end{array}$

4812.0016 .0000

$\begin{array}{lll}36 & 8.95 & 7.9000\end{array}$

$\begin{array}{lll}20 & 6.60 & 10.7000\end{array}$

$55 \quad 40.0059 .0000$

$20 \quad 6.9013 .1800$

187
Random effects model 187

Heterogeneity: $l^{2}=84 \%, \tau^{2}=198.032, p<0.001$

Test for overall effect: $z=7.110(p<0.001)$

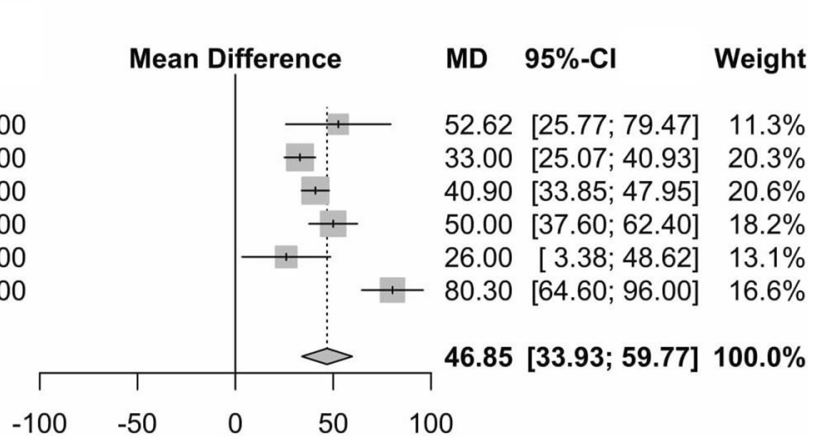

and post-treatment using budesonide [30, 40-44] (c). CI confidence interval, $M D$ mean difference, $R R$ risk ratio, $S D$ standard deviation
Fig. 2 Forest plot meta-analysis for histological response [14, 45-48] (a) and mean change in eosinophil count $[29,47,48]$ (b) with budesonide versus placebo and for mean change in eosinophil count pre- randomized and non-randomized research studies reporting the efficacy of budesonide in the management of EE. To the best of our knowledge, this is the first systematic review and meta-analysis aimed at shedding light on the potential role of budesonide in patients with EE through analysis of all of the published original studies on this topic. Our results show that budesonide has considerable effects in terms of histological remission and improvement of clinical symptoms. Moreover, the eosinophilic count has been reduced markedly with budesonide treatment. However, patients taking budesonide had an increased risk of candidiasis.

The treatment endpoints may vary between clinicians and patients. For instance, patients are mostly concerned with relieving the clinical complaints and improving their quality of life, while clinicians seek good histological response and lessening endoscopic abnormalities [52]. However, eosinophil count remains one of the most important treatment endpoints. Fortunately, our meta-analysis revealed that patients in the budesonide-treated group compared with placebo controls and who received pre-treatment compared with post-treatment with budesonide experienced considerable reduction in the eosinophil count. However, it is worth mentioning that there are factors against approving the eosinophil count as a sole standard treatment endpoint, one of which is the different histologic diagnostic cutoff values used in the included studies. However, most of the included studies used the reduction in eosinophils to less than 15 eos/hpf as the main treatment endpoint, which is consistent with the guidelines from the European Society for Paediatric Gastroenterology Hepatology and Nutrition (ESPGHAN) and American Society of Gastroenterology (ACG) $[53,54]$. Another issue is how the researchers count 
A

Study

Dellon/2016/USA
Dohil/2010/USA
Straumann/2010/USA

Fixed effect model

Heterogeneity: $I^{2}=12 \%, \tau^{2}=0.014, p=0.321$

Test for overall effect: $z=3.113(p=0.002)$

B

\section{Experimental Control Events Total Events Total}

\section{al}

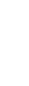

Risk Ratio RR $95 \%-\mathrm{Cl} \quad$ Weight

$\begin{array}{rrr}31 & 49 & 15 \\ 12 & 15 & 5 \\ 13 & 18 & \\ & \\ & 82 \\ =0.014, p=0.321 & =0.002) \\ 113(p=0.00 & \end{array}$

38

9

18

65

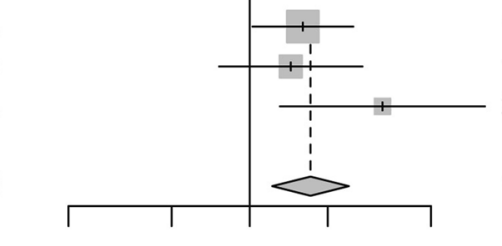

$1.60[1.02 ; 2.51] \quad 57.6 \%$

$1.44[0.76 ; 2.72] \quad 28.5 \%$

$3.25[1.31 ; 8.08] \quad 13.9 \%$

$1.72[1.22 ; 2.41] 100.0 \%$

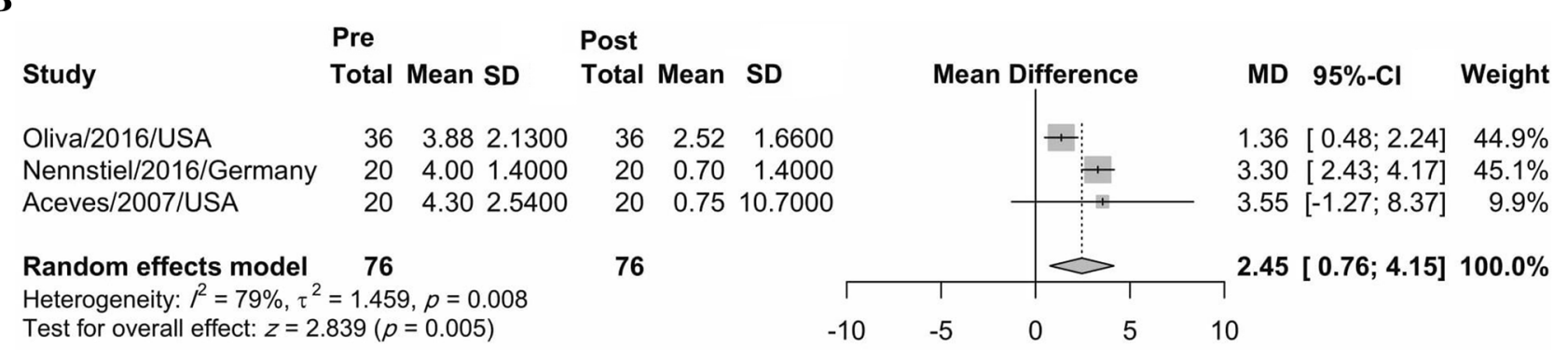

Fig. 3 Forest plot meta-analysis for clinical response with budesonide versus placebo [29, 47, 48] (a) and mean clinical scores pre- and postbudesonide treatment $[30,43,44]$ (b). $C I$ confidence interval, $M D$ mean difference, $R R$ risk ratio, $S D$ standard deviation

the eosinophils; a systematic review of the literature found that some studies used the peak eosinophil count while other researchers prefer to use a mean count from multiple fields [55]. Moreover, the eosinophil count may vary with different locations of the esophageal biopsy, which is why researchers have recommended utilizing multiple biopsy locations for proper diagnosis [56].

Improvement of clinical symptoms is also considered a substantial treatment endpoint, especially from a patient's perspectives. Our meta-analysis of randomized and non-randomized studies revealed significant improvement in clinical symptoms after receiving budesonide, and significant heterogeneity was found with the non-randomized studies. Different questionnaires have been implemented to evaluate the clinical response but only the EEsAI and DSQ were validated $[57,58]$. The authors of the two analyzed RCTs used the DSQ questionnaire [29, 45]. Nevertheless, clinicians cannot assume histological remission or resolution of endoscopic abnormalities based on symptoms relief. Such dissociation between clinical features and histological and endoscopic findings has been reported in both adults and pediatric patients with EE $[59,60]$.

In addition to good clinical response, our analysis showed a significant improvement of endoscopic abnormalities (furrows, rings, edema, structure, and white specks/plaques/ exudates), which is also an important treatment endpoint. One of the methods to assess the endoscopic abnormalities and monitor treatment effect is the EREFS, which has been tested by a prospective study as a scoring system for such abnormalities [61]. More than one study contributed to the analysis of esophageal furrows, rings, and stricture, but only one study reported a decrease in the esophageal narrowing [39]. It has been reported that the optimal diameter of esophageal lumen is about 15 and $18 \mathrm{~mm}$ to smoothly ingest regular modified food and full meal, respectively.

The main strength of our study is that it is the first metaanalysis, to our knowledge, to assess the efficacy and safety of budesonide in the treatment of EE. Another strength of our meta-analysis is that we included more studies and analyzed more outcomes than the previous meta-analysis. We believe that budesonide is worth examining further via largepopulation randomized studies. Nevertheless, our study has several limitations. One important limitation is the small number of included studies and participants, which precludes the standardization of budesonide for all patients with EE in clinical practice. Another limitation is the significant heterogeneity between the different studies regarding the outcomes of eosinophil count and clinical response. Moreover, different values for histologic diagnostic criteria were noticed between studies, which in turn alters the definition of responders between studies. The variation in the followup duration between included studies may also manipulate the results. Our study pooled both adults and children in one analysis and we could not perform meta-regression of age or of other factors such as sex and publication year due to the small number of included studies. Future well-designed randomized studies including adequate populations should consider these limitations. 
A

Study Events Total Events Tota

Edema/decreased vascularization

\begin{tabular}{lrrrr} 
Reed/2018/USA & 32.0 & 48 & 12.0 & 33 \\
Nennstiel/2016/Germany & 0.8 & 20 & 0.3 & 20 \\
Eluri/2017/USA & 14.0 & 55 & 14.0 & 55 \\
Fixed effect model & \multicolumn{1}{c}{123} & & 108 \\
Test for effect in subgroup: $z=1.940(p=0.052)$ &
\end{tabular}

Furrows

\begin{tabular}{lrrrr} 
Fable/2017/USA & 29.0 & 48 & 11.0 & 48 \\
Reed/2018/USA & 40.0 & 48 & 12.0 & 33 \\
Nennstiel/2016/Germany & 1.5 & 20 & 0.5 & 20 \\
Eluri/2017/USA & 38.0 & 55 & 19.0 & 55 \\
Fixed effect model & \multicolumn{5}{c}{171} \\
Test for effect in subgroup: $z=5.860(p<0.001)$ & &
\end{tabular}

Narrowing

$\begin{array}{lllll}\text { Reed/2018/USA } & 14.0 & 48 & 11.0 & 33\end{array}$

Fixed effect model $\quad 48 \quad 33$

Test for effect in subgroup: $z=-0.400(p=0.689)$

Rings/trachealization

\begin{tabular}{lrrrr} 
Fable/2017/USA & 3.0 & 48 & 4.0 & 48 \\
Reed/2018/USA & 39.0 & 48 & 18.0 & 33 \\
Nennstiel/2016/Germany & 2.0 & 20 & 1.1 & 20 \\
Eluri/2017/USA & 44.0 & 55 & 27.0 & 55 \\
Fixed effect model & \multicolumn{2}{c}{171} & & 156 \\
Test for effect in subgroup: $z=3.841(p<0.001)$ &
\end{tabular}

Strictures

\begin{tabular}{lrrrr} 
Reed/2018/USA & 27.0 & 48 & 15.0 & 33 \\
Eluri/2017/USA & 20.0 & 55 & 15.0 & 55 \\
Fixed effect model & \multicolumn{5}{c}{103} \\
Test for effect in subgroup: $z=1.361(p=0.173)$ &
\end{tabular}

White specks/plaques/excudates

\begin{tabular}{lrrrr} 
Fable/2017/USA & 16.0 & 48 & 2.0 & 48 \\
Nennstiel/2016/Germany & 1.0 & 20 & 0.2 & 20 \\
Eluri/2017/USA & 23.0 & 55 & 17.0 & 55 \\
Fixed effect model & \multicolumn{3}{c}{123} & \\
Test for effect in subgroup: $z=2.130(p=0.033)$ &
\end{tabular}

Fixed effect model

739

Heterogeneity: $I^{2}=23 \%, \tau^{2}=0.025, p=0.186$

Test for overall effect: $z=6.949(p<0.001)$

664

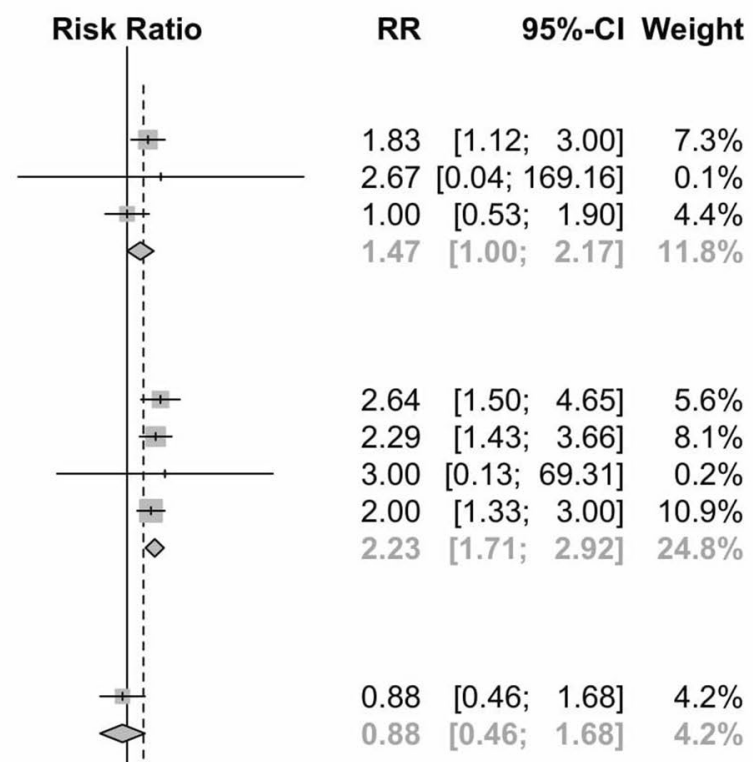

B

Study

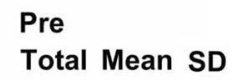

Post

$\begin{array}{lllllll}\text { Aceves/2007/USA } & 20 & 3.60 & 1.7300 & 20 & 0.65 & 0.9300 \\ \text { Eluri/2017/USA } & 55 & 2.60 & 1.4000 & 55 & 2.40 & 1.5000 \\ \text { Nennstiel/2016/Germany } & 20 & 5.40 & 2.6000 & 20 & 2.00 & 1.5000 \\ \text { Oliva/2016/USA } & 36 & 4.72 & 2.1300 & 36 & 2.11 & 1.4200\end{array}$

Random effects model 131

131

Heterogeneity: $l^{2}=94 \%, \tau^{2}=2.631, p<0.001$

Test for overall effect: $z=2.659(p=0.008)$

MD $95 \%-\mathrm{Cl} \quad$ Weight

$2.95[2.09 ; 3.81] \quad 25.2 \%$

$0.20[-0.34 ; 0.74] \quad 26.3 \%$

$3.40[2.08 ; 4.72] \quad 23.1 \%$

$2.61[1.77 ; 3.45] \quad 25.3 \%$

$2.24[0.59 ; 3.90] 100.0 \%$

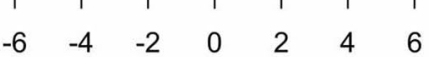

Fig. 4 Forest plot meta-analysis for endoscopic abnormalities [39, 41-43] (a) and mean esophageal scores [30, 42-44] (b) pre- and post-budesonide treatment. $C I$ confidence interval, $M D$ mean difference, $R R$ risk ratio, $S D$ standard deviation 


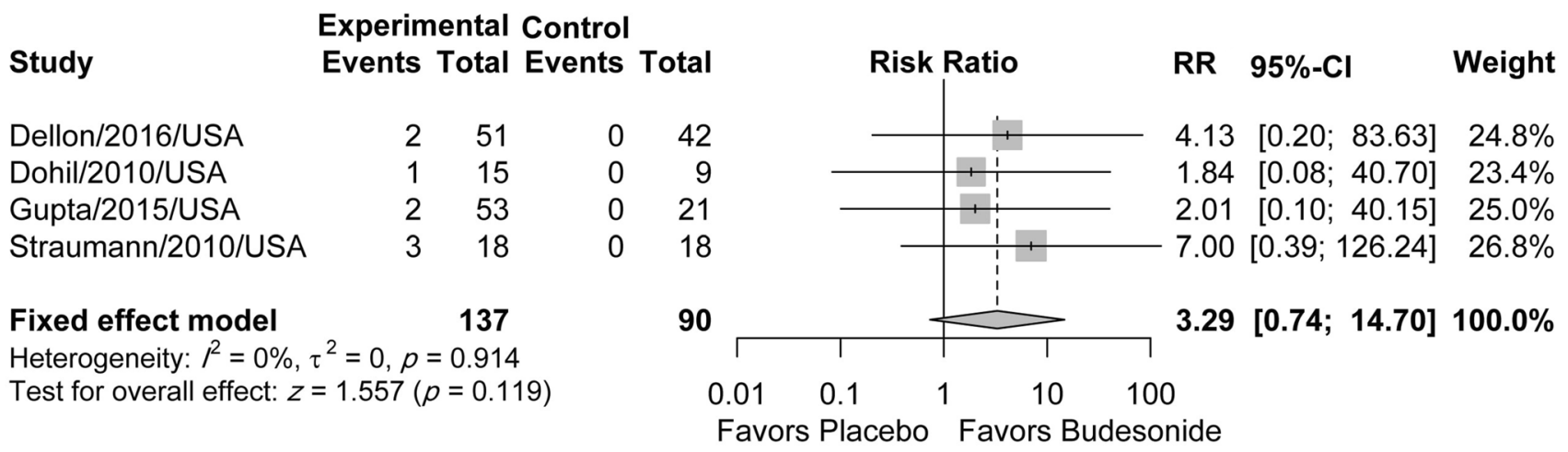

Fig. 5 Forest plot meta-analysis for incidence of candidiasis with budesonide versus placebo [29, 45, 47, 48]. $C I$ confidence interval, $R R$ risk ratio

\section{Conclusion}

Budesonide may have promise in lessening the eosinophilic count and inducing histological remission in patients with EE. Furthermore, budesonide can reduce the endoscopic abnormalities and improve the clinical status of those patients. Since it carries the risk for candidiasis and our inferences are based on a small number of studies, these findings should be interpreted with caution. Future largescale randomized studies are desired before we can make conclusive inferences and construct a standard treatment protocol.

Author Contributions P.R. participated in the design of the study. All authors participated in the screening of articles, extraction of data, analysis, writing, and approval of the manuscript.

Funding This work was not supported by any funder.

\section{Compliance with Ethical Standards}

Conflict of Interest Prashanth Rawla, Tagore Sunkara, Krishna Chaitanya Thandra, and Vinaya Gaduputi declare no conflict of interest.

Open Access This article is distributed under the terms of the Creative Commons Attribution-NonCommercial 4.0 International License (http://creativecommons.org/licenses/by-nc/4.0/), which permits any noncommercial use, distribution, and reproduction in any medium, provided you give appropriate credit to the original author(s) and the source, provide a link to the Creative Commons license, and indicate if changes were made.

\section{References}

1. Dellon ES, Gonsalves N, Hirano I, Furuta GT, Liacouras CA, Katzka DA. ACG clinical guideline: evidenced based approach to the diagnosis and management of esophageal eosinophilia and eosinophilic esophagitis (EoE). Am J Gastroenterol. 2013;108(5):679-692 (quiz 693).

2. Noel RJ, Putnam PE, Rothenberg ME. Eosinophilic esophagitis. N Engl J Med. 2004;351(9):940-1.

3. Potter JW, Saeian K, Staff D, Massey BT, Komorowski RA, Shaker R, Hogan WJ. Eosinophilic esophagitis in adults: an emerging problem with unique esophageal features. Gastrointest Endosc. 2004;59(3):355-61.

4. Liacouras CA, Ruchelli E. Eosinophilic esophagitis. Curr Opin Pediatr. 2004;16(5):560-6.

5. Robson J, O'Gorman M, McClain A, Mutyala K, Davis C, Barbagelata $\mathrm{C}$, et al. Incidence and prevalence of pediatric eosinophilic esophagitis in Utah based on a 5-year population-based study. Clin Gastroenterol Hepatol. Epub 2018 Jun 20. https:// doi.org/10.1016/j.cgh.2018.06.028.

6. van Rhijn BD, Verheij J, Smout AJ, Bredenoord AJ. Rapidly increasing incidence of eosinophilic esophagitis in a large cohort. Neurogastroenterol Motil. 2013;25(1):47-52.e45.

7. Kagalwalla AF, Sentongo TA, Ritz S, Hess T, Nelson SP, Emerick KM, et al. Effect of six-food elimination diet on clinical and histologic outcomes in eosinophilic esophagitis. Clin Gastroenterol Hepatol. 2006;4(9):1097-102.

8. Sundaram S, Sunku B, Nelson SP, Sentongo T, Melin-Aldana $\mathrm{H}$, Kumar R, et al. Adherent white plaques: an endoscopic finding in eosinophilic esophagitis. J Pediatr Gastroenterol Nutr. 2004;38(2):208-12.

9. Fogg MI, Ruchelli E, Spergel JM. Pollen and eosinophilic esophagitis. J Allergy Clin Immunol. 2003;112(4):796-7.

10. Ram G, Lee J, Ott M, Brown-Whitehorn TF, Cianferoni A, Shuker M, et al. Seasonal exacerbation of esophageal eosinophilia in children with eosinophilic esophagitis and allergic rhinitis. Ann Allergy Asthma Immunol. 2015;115(3):224-228.e1.

11. Mishra A, Hogan SP, Brandt EB, Rothenberg ME. An etiological role for aeroallergens and eosinophils in experimental esophagitis. J Clin Invest. 2001;107(1):83-90.

12. Dellon ES, Liacouras CA, Molina-Infante J, Furuta GT, Spergel $\mathrm{JM}$, Zevit N, et al. Updated international consensus diagnostic criteria for eosinophilic esophagitis: Proceedings of the AGREE conference. Gastroenterology 2018;155(4):1022.e10-1033.e10.

13. Fox VL, Nurko S, Furuta GT. Eosinophilic esophagitis: it's not just kid's stuff. Gastrointest Endosc. 2002;56(2):260-70.

14. Dellon ES, Cotton CC, Gebhart JH, Higgins LL, Beitia R, Woosley JT, et al. Accuracy of the eosinophilic esophagitis endoscopic reference score in diagnosis and determining response to treatment. Clin Gastroenterol Hepatol. 2016;14(1):31-9. 
15. Guyatt GH, Feeny DH, Patrick DL. Measuring health-related quality of life. Ann Intern Med. 1993;118(8):622-9.

16. Schoepfer A, Straumann A, Safroneeva E. Patient-reported outcomes in eosinophilic esophagitis and achalasia. Curr Treat Options Gastroenterol. 2016;14(1):51-60.

17. Hirano I, Aceves SS. Clinical implications and pathogenesis of esophageal remodeling in eosinophilic esophagitis. Gastroenterol Clin. 2014;43(2):297-316.

18. Nurko S, Furuta GT. Eosinophilic esophagitis. GI Motility Online 2006. https://doi.org/10.1038/gimo49.

19. Cotton CC, Eluri S, Wolf WA, Dellon ES. Six-food elimination diet and topical steroids are effective for eosinophilic esophagitis: a meta-regression. Dig Dis Sci. 2017;62(9):2408-20.

20. Asher Wolf W, Huang KZ, Durban R, Iqbal ZJ, Robey BS, Khalid FJ, et al. The six-food elimination diet for eosinophilic esophagitis increases grocery shopping cost and complexity. Dysphagia. 2016;31(6):765-70.

21. Dellon ES, Liacouras CA. Advances in clinical management of eosinophilic esophagitis. Gastroenterology. 2014;147(6):1238-54.

22. Peterson KA, Byrne KR, Vinson LA, Ying J, Boynton KK, Fang $\mathrm{JC}$, et al. Elemental diet induces histologic response in adult eosinophilic esophagitis. Am J Gastroenterol. 2013;108(5):759-66.

23. Spergel JM, Beausoleil JL, Mascarenhas M, Liacouras CA. The use of skin prick tests and patch tests to identify causative foods in eosinophilic esophagitis. J Allergy Clin Immunol. 2002;109(2):363-8.

24. Greenhawt M, Aceves SS, Spergel JM, Rothenberg ME. The management of eosinophilic esophagitis. J Allergy Clin Immunol Pract. 2013;1(4):332-40.

25. Philpott H, Nandurkar S, Royce S, Thien F, Gibson P. Allergy tests do not predict food triggers in adult patients with eosinophilic oesophagitis. A comprehensive prospective study using five modalities. Aliment Pharmacol Ther 2016;44(3):223-33.

26. Gonzalez-Cervera J, Lucendo AJ. Eosinophilic esophagitis: an evidence-based approach to therapy. J Investig Allergol Clin Immunol 2016;26(1):8-18 (quiz 2p following 18).

27. Lipka S, Kumar A, Miladinovic B, Richter JE. Systematic review with network meta-analysis: comparative effectiveness of topical steroids vs. PPIs for the treatment of the spectrum of eosinophilic oesophagitis. Aliment Pharmacol Ther 2016;43(6):663-73.

28. Murali AR, Gupta A, Attar BM, Ravi V, Koduru P. Topical steroids in eosinophilic esophagitis: Systematic review and metaanalysis of placebo-controlled randomized clinical trials. J Gastroenterol Hepatol. 2016;31(6):1111-9.

29. Dellon ES, Katzka DA, Collins MH, Hamdani M, Gupta SK, Hirano I. Budesonide oral suspension improves symptomatic, endoscopic, and histologic parameters compared with placebo in patients with eosinophilic esophagitis. Gastroenterology. 2017;152(4):776-786.e775.

30. Oliva S, Rossetti D, Papoff P, Tiberti A, Rossi P, Isoldi S, et al. A new formulation of oral viscous budesonide in treating paediatric eosinophilic oesophagitis: a pilot study. J Pediatr Gastroenterol Nutr. 2017;64(2):218-24.

31. Shrier I, Boivin JF, Steele RJ, Platt RW, Furlan A, Kakuma R, et al. Should meta-analyses of interventions include observational studies in addition to randomized controlled trials? A critical examination of underlying principles. Am J Epidemiol. 2007;166(10):1203-9.

32. Moher D, Liberati A, Tetzlaff J, Altman DG. Preferred reporting items for systematic reviews and meta-analyses: the PRISMA statement. PLoS Med. 2009;6(7):e1000097.

33. Team RC. R: a language and environment for statistical computing. Vienna: R Foundation for Statistical Computing; 2017.
34. Hedges LV, Pustejovsky JE, Shadish WR. A standardized mean difference effect size for multiple baseline designs across individuals. Res Synth Methods. 2013;4(4):324-41.

35. Schwarzer G. meta: an R package for meta-analysis. R News. 2007;7(3):40-5.

36. Mantel N, Haenszel W. Statistical aspects of the analysis of data from retrospective studies of disease. J Natl Cancer Inst. 1959;22(4):719-48.

37. DerSimonian R, Laird N. Meta-analysis in clinical trials. Control Clin Trials. 1986;7(3):177-88.

38. Higgins JPT, Thompson SG, Deeks JJ, Altman DG. Measuring inconsistency in meta-analyses. BMJ. 2003;327(7414):557-60.

39. Reed CC, Fan C, Koutlas N, Stefanadis Z, Eluri S, Shaheen NJ, et al. Compounded oral viscous budesonide is effective and provides a durable response in eosinophilic esophagitis. HSOA J Gastroenterol Hepatol Res. 2018;7(1):2509-15.

40. Rubinstein E, Hait EE, Mitchell PD, Lee JJ. Every-other-day dosing of oral viscous budesonide is not effective in the management of eosinophlic esophagitis. J Pediatr Gastroenterol Nutr. 2018;66(3):395-7.

41. Fable JM, Fernandez M, Goodine S, Lerer T, Sayej WN. Retrospective comparison of fluticasone propionate and oral viscous budesonide in children with eosinophilic esophagitis. J Pediatr Gastroenterol Nutr. 2018;66(1):26-32.

42. Eluri S, Runge TM, Hansen J, Kochar B, Reed CC, Robey BS, et al. Diminishing effectiveness of long-term maintenance topical steroid therapy in PPI non-responsive eosinophilic esophagitis. Clin Transl Gastroenterol. 2017;8(6):e97.

43. Nennstiel S, Bajbouj M, Becker V, Slotta-Huspenina J, Wagenpfeil $\mathrm{S}$, Schmid RM, et al. High-resolution manometry in patients with eosinophilic esophagitis under topical steroid therapy-a prospective observational study (HIMEOS-study). Neurogastroenterol Motil. 2016;28(4):599-607.

44. Aceves SS, Bastian JF, Newbury RO, Dohil R. Oral viscous budesonide: a potential new therapy for eosinophilic esophagitis in children. Am J Gastroenterol. 2007;102(10):2271-79 (quiz 2280).

45. Gupta SK, Vitanza JM, Collins MH. Efficacy and safety of oral budesonide suspension in pediatric patients with eosinophilic esophagitis. Clin Gastroenterol Hepatol. 2015;13(1):66-76.e63.

46. Miehlke S, Hruz P, Vieth M, Bussmann C, von Arnim U, Bajbouj $\mathrm{M}$, et al. A randomised, double-blind trial comparing budesonide formulations and dosages for short-term treatment of eosinophilic oesophagitis. Gut. 2016;65(3):390-9.

47. Straumann A, Conus S, Degen L, Felder S, Kummer M, Engel $\mathrm{H}$, et al. Budesonide is effective in adolescent and adult patients with active eosinophilic esophagitis. Gastroenterology 2010;139(5):1526-37 (1537.e1521).

48. Dohil R, Newbury R, Fox L, Bastian J, Aceves S. Oral viscous budesonide is effective in children with eosinophilic esophagitis in a randomized, placebo-controlled trial. Gastroenterology. 2010;139(2):418-29.

49. Higgins JP, Altman DG, Gotzsche PC, Juni P, Moher D, Oxman $\mathrm{AD}$, et al. The Cochrane Collaboration's tool for assessing risk of bias in randomised trials. BMJ. 2011;343:d5928.

50. Lo CK, Mertz D, Loeb M. Newcastle-Ottawa Scale: comparing reviewers' to authors' assessments. BMC Med Res Methodol. 2014;14:45.

51. Aceves S, Newbury R, Chen D, Mueller J, Dohil R, Hoffman H, et al. Resolution of remodeling in eosinophilic esophagitis correlates with epithelial response to topical corticosteroids. Allergy. 2010;65(1):109-16.

52. Shah NA, Albert DM, Hall NM, Moawad FJ. Managing eosinophilic esophagitis: challenges and solutions. Clin Exp Gastroenterol. 2016;9:281-90. 
53. Furuta GT, Liacouras CA, Collins MH, Gupta SK, Justinich C, Putnam PE, et al. Eosinophilic esophagitis in children and adults: a systematic review and consensus recommendations for diagnosis and treatment: sponsored by the American Gastroenterological Association (AGA) Institute and North American Society of Pediatric Gastroenterology, Hepatology, and Nutrition. Gastroenterology. 2007;133(4):1342-63.

54. Papadopoulou A, Koletzko S, Heuschkel R, Dias J, Allen K, Murch S, et al. Management guidelines of eosinophilic esophagitis in childhood. J Pediatr Gastroenterol Nutr. 2014;58(1):107-18.

55. Dellon ES, Aderoju A, Woosley JT, Sandler RS, Shaheen NJ. Variability in diagnostic criteria for eosinophilic esophagitis: a systematic review. Am J Gastroenterol. 2007;102(10):2300-13.

56. Dellon ES, Speck O, Woodward K, Covey S, Rusin S, Shaheen NJ, et al. Distribution and variability of esophageal eosinophilia in patients undergoing upper endoscopy. Mod Pathol. 2015;28(3):383-90.

57. Schoepfer AM, Straumann A, Panczak R, Coslovsky M, Kuehni CE, Maurer E, et al. Development and validation of a symptom-based activity index for adults with eosinophilic esophagitis. Gastroenterology. 2014;147(6):1255-1266.e1221.

58. Dellon ES, Irani AM, Hill MR, Hirano I. Development and field testing of a novel patient-reported outcome measure of dysphagia in patients with eosinophilic esophagitis. Aliment Pharmacol Ther. 2013;38(6):634-42.

59. Safroneeva E, Straumann A, Coslovsky M, Zwahlen M, Kuehni $\mathrm{CE}$, Panczak R, et al. Symptoms have modest accuracy in detecting endoscopic and histologic remission in adults with eosinophilic esophagitis. Gastroenterology. 2016;150(3):581-590.e584.

60. Pentiuk S, Putnam PE, Collins MH, Rothenberg ME. Dissociation between symptoms and histological severity in pediatric eosinophilic esophagitis. J Pediatr Gastroenterol Nutr. 2009;48(2):152-60.

61. Hirano I, Moy N, Heckman MG, Thomas CS, Gonsalves N, Achem SR. Endoscopic assessment of the oesophageal features of eosinophilic oesophagitis: validation of a novel classification and grading system. Gut. 2013;62(4):489-95. 